\title{
The role of airway remodeling in the pathogenesis and treatment of chronic obstructive pulmonary disease
}

\begin{abstract}
Chronic obstructive pulmonary disease (COPD) is currently considered the third leading cause of death in the world. COPD represents an important public health challenge and a socio-economical problem that is preventable and treatable. The main cause of COPD is chronic inhalation of cigarette smoke, and other harmful constituents of air pollution, which cause epithelial injury, chronic inflammation and airway remodeling. Airway remodeling is most prominent in small airways. It is due to infiltration of the airways by inflammatory cells, such as neutrophils, eosinophils, macrophages, and immune cells, including CD8+ T-cells, Th1, Th17 lymphocytes, and innate lymphoid cells group 3. Fibroblasts, myofibroblasts, and airway smooth muscle (ASM) cells also contribute to airway remodeling by depositing extracellular matrix (ECM) proteins, which increase the thickness of the airway wall. Activated inflammatory cells, and structural cells secrete cytokines, chemokines, growth factors, and enzymes which propagate airway remodeling. Airway remodeling is an active process which leads to thickness of the reticular basement membrane, subepithelial fibrosis, peribronchiolar fibrosis, and ASM cells hyperplasia and hypertrophy. It is also accompanied by submucosal glands and goblet cells hypertrophy and mucus hypersecretion, and angiogenesis. Epithelial mesenchymal transmission (EMT) plays a key role in airway remodeling. In patients with COPD and smokers, cellular reprograming in epithelial cells leads to EMT, whereby epithelial cells assume a mesencymal phenotype. Additionally, COPD is associated with increased parasympathetic cholinergic activity, which leads to ASM cells hypercontractility, increased mucus secretion, and vasodilatation. Treatment of COPD is intricate because of the heterogeneous nature of the disease, which requires specific treatment of the pathophysiological pathways, such as airway inflammation, ASM cell hypercontractility, and parasympathetic cholinergic hyperreactivity. The Global Initiative for Chronic Obstructive Lung Disease (GOLD) 2020 strategy report recommends personalized approach for the treatment of COPD. However, some patients with COPD are unresponsive to the standards of care. They may require a triple combination of LABA/ LAMA/ICS. Single-inhaler triple therapy (SITT), such as fluticasone fuorate/vilanterol/ umeclidinium has been shown to significantly improve symptoms and asthma control, reduce moderate and severe exacerbations, and to improve lung function.
\end{abstract}

Volume 8 Issue 3 - 2021

\author{
Nightingale Syabbalo \\ Professor of Physiology and Medicine, Nabanji Medical Centre, \\ Zambia
}

Correspondence: Professor N. Syabbalo, Professor of Physiology and Medicine, Nabanji Medical Centre, O. Box 30243, Lusaka, Zambia, Tel +260966 486II7,

Email nightsyab@gmail.com

Received: June 9, 2021 | Published: July 22, 2021

Keywords: airway remodeling, COPD, EMT, triple therapy

\section{Introduction}

Chronic obstructive pulmonary disease (COPD) is currently considered the third leading cause of death in the world, ${ }^{1,2}$ and its prevalence, especially the milder form, is estimated to be about $25 \%$ of adults above 40 years. ${ }^{3}$ COPD represents an important public health challenge, and socio-economical problem that is preventable and treatable. It is a major cause of morbidity and mortality, which is projected to rise in the coming decade due to continuous exposure to cigarette smoke, particularly in low-and-middle-income countries. ${ }^{4,5}$ The main cause of COPD is chronic inhalation of cigarette smoke, and other indoor and outdoor harmful constituents of air pollution, ${ }^{6,7}$ which cause epithelial injury, chronic inflammation, and airway remodeling.

Severe COPD is characterized by frequent exacerbations. Exacerbations are the most disruptive aspect of COPD, and frequent exacerbations are associated with disease progression, decreasing lung function, worsening quality of life, and decreased physical activity levels. Frequent COPD exacerbations can have considerable impact on healthcare costs, and contributes to high mortality rate. ${ }^{8}$ Exacerbations require precision and personalized treatment targeting all the pathophysiological mechanisms of airway remodeling, which contributes to the severity of the disease.

Airway remodeling is a hallmark of asthma, but it also occurs in patients with chronic obstructive pulmonary disease. It involves mostly peripheral small airways, ${ }^{9-11}$ and to a lesser extent larger airways, ${ }^{12}$ causing thickening of the airway wall, and narrowing of the bronchial lumen..$^{9-11,13}$ The airway structural changes lead to increase in airflow resistance, progressive and irreversible decline in pulmonary function, ${ }^{14,15}$ which correlates with the severity of COPD. ${ }^{6}$

\section{Airway remodeling in COPD}

Airway remodeling is an active process leading to epithelial cells metaplasia and desquamation; deposition of extracellular matrix (ECM) proteins by fibroblasts, and myofibroblasts; thickness of the reticular basement membrane; subepithelial fibrosis; peribronchial fibrosis; and ASM cells hyperplasia and hypertrophy. ${ }^{9-15}$ It is also accompanied by submucosal glands and, goblet cell hypertrophy and mucus hypersecretion, ${ }^{16,17}$ angiogenesis, ${ }^{18,19}$ and enhanced parasympathetic cholinergic activity. ${ }^{20}$ Peribronchiolar fibrosis plays 
an important role in stiffening the bronchiolar walls, increasing airflow resistance, and progressive decline in pulmonary function (low FEV1). ${ }^{21-23}$ Table 1 outlines the pathophysiological mechanisms of airway remodeling in COPD.

Table I Mechanisms of airway remodeling in patients with chronic obstructive pulmonary disease

Epithelial inflammation due cigarette smoke, and pollutants
Epithelial cell metaplasia and desquamation
Release of cytokines, chemokines, growth factors, enzymes, and adhesion molecules
Submucosal glands and goblet cell hyperplasia, and mucus hypersecretion
Epithelial mesenchymal transition
Activation of fibroblasts, and myofibroblasts
Deposition of extracellular matrix proteins
Reticular basement membrane thickening, and subepithelial fibrosis
Peribronchiolar fibrosis
Airway smooth muscle hyperplasia, and hypertrophy
Angiogenesis, and exaggerated vasodilatation
Increase in parasympathetic cholinergic activity
Corticosteroid-resistance due to non-neuronal cholinergic system

\section{Inflammatory and immune cells}

Inflammatory cells, such as neutrophils, eosinophils, CD68+ macrophages, mast cells, ${ }^{24-26}$ and immune cells, including CD8+ $\mathrm{T}$ cells, Th1, Th17 lymphocytes, and innate lymphoid cells group $3,{ }^{27,28}$ play a key role in airway inflammation and remodeling. They secrete inflammatory cytokines, chemokines, growth factors, adhesion molecules, and enzymes which orchestrates the remodeling process. Metalloproteinases (MMPs), especially MMP-9 secreted by neutrophils and macrophages play an important role in airway remodeling in patients with COPD and asthma. ${ }^{25}$ Integrins play a supportive role in propagating airway hyperresponsiveness, remodeling, ${ }^{29,30}$ and act synergistically with vascular endothelial growth factor (VEGF) to promote angiogenesis. ${ }^{19,31}$

Several chemokines, cytokines, growth factors secreted by activated inflammatory and immune cells, and structural cells participate in the airway remodeling process. They include chemokines, such as RANTES and eotaxins ${ }^{27}$ cytokines, including interleukin- $1 \beta$ (IL-1 $\beta$ ), IL-6, IL-8, IL-22, and TNF- $\alpha \cdot{ }^{29,32-36}$ and growth factors, such as TGF $\beta$, FGF, EGFR, and IGF. ${ }^{29,37-40}$ Table 2 shows the inflammatory mediators and growth factors responsible for airway remodeling in COPD.

\section{Epithelial mesenchymal transition in COPD}

Airway epithelial cells form the first line of defense against external insults, such as infectious microbes, allergens, toxic particulate matter, such as cigarette smoke, noxious pollutants, and gases. ${ }^{41}$ Epithelial cells are both proliferative and secretory. They produce and secrete several anti-bacterial peptides, antioxidants, proteases, antiproteases, ${ }^{42}$ cytokines and growth factors,${ }^{43,44}$ which propagate airway inflammation and remodeling. Inflammatory mediators and growth factors also promote epithelial mesenchymal transition (EMT). EMT plays a key role in airway remodeling in patients with COPD, and asthma. In patients with COPD and smokers, cellular reprogramming in epithelial cells ${ }^{45}$ could lead to epithelial-mesenchymal transition, ${ }^{46}$ whereby epithelial cells progressively lose cellular polarity, and adhesiveness, and become migratory and assume a mesenchymal phenotype. ${ }^{47-50}$ During EMT, epithelial cells lose epithelial markers, such as E-cadherin, KRT5, KRT18, and ZO-1,,$^{51,52}$ and exhibit significant increase in mRNA transcripts and protein expression for mesenchymal markers, such as $\alpha$-smooth muscle actin ( $\alpha$-SMA), vimentin, and collagen $1 .^{52,53}$ One of the characteristic features of EMT is thickening and fragmentation of the reticular basement, which is due to increase in epithelial matrix metalloprotease activity, especially MMP-9. ${ }^{47}$

Table 2 Inflammatory mediators and growth factors involved in airway remodeling, angiogenesis, and mucus secretion in COPD

\begin{tabular}{ll}
\hline Cytokines & Chemokines \\
\hline IL-I $\beta$ & RANTES \\
IL-6 & Eotaxins \\
IL-8/CXCL8 & Gro- $\alpha$ \\
IL-22 & Adhesion molecules \\
TNF- $\alpha$ & Integrins (VCAM, ICAM, MAdCAM) \\
MCP-I & Mucus secretion \\
Growth factors & EGFR \\
TGF- $\beta$ & Angiogenic factors \\
bFGF-I & VEGF \\
EGF & Angiopoietin-I \\
IGF & IL-8/CXCL8 \\
\hline
\end{tabular}

Abbreviations: bFGF, basic-fibroblast growth factor; EGF, epidermal growth factor; EGFR, epidermal growth factor receptor; Gro- $\alpha$, growthregulated oncogene; IGF, insulin-like growth factor; IL, interleukin; MCP-I, monocyte chemotactic peptide-I; RANTES, regulated on activation, normal T-cell expressed and secreted;TGF, transforming growth factor; TNF, tumour necrosis factor;VEGF, vascular endothelial growth factor

Transforming growth factor- $\beta$ plays an important role in the induction of the EMT, and the TGF- $\beta$ pathway is up-regulated in the 
bronchial epithelium of smokers and patients with COPD..$^{54}$ EMT is most active in small airways of smokers and patients with COPD, ${ }^{47,53}$ leading to excessive deposition of ECM proteins by fibroblasts, and myoblasts, increasing airway wall thickeness, and airflow obstruction..$^{54,55}$

Airway remodeling also involves accumulation of myofibroblasts due to fibroblast-myofibroblast transition, ASM cell transition to myofibroblast, ${ }^{48}$ and endothelial cell transition to myofibroblast or by the recruitment of circulating fibroblastic stem cells (fibrocytes). ${ }^{47}$ TGF- $\beta$, IL-13, and connective tissue growth factor have been described to induce myofibroblast transition. ${ }^{55-57}$ The transformed myofibroblasts acquire a more proliferative, contractile and secretoryactive myofiboblast phenotype. They acquire increased expression of extracellular matrix components, such as, vimentin, collagen type 1, and $\alpha$-smooth muscle actin. ${ }^{58}$ The mechanisms by which fibroblasts transform into myofibroblast phenotype is believed to be mediated by increase in intracellular reactive oxygen species, decrease in cyclic AMP (cAMP), and phosphorylation of the extracellular signalregulated kinase $1 / 2\left(\right.$ ERK1/2). ${ }^{59}$

EMT, and fibroblast to myofibroblast transition play a key role in the deposition of ECM proteins, subepithelial fibrosis, and peribronchiolar fibrosis, ${ }^{57}$ which contributes to partial or total irreversible airway obstruction, and decline in pulmonary function in patients with COPD.

\section{Parasympathetic cholinergic activity in COPD}

Parasympathetic cholinergic activity to the airways is increased in patients with COPD ${ }^{20,60-63}$ leading to ASM cells hypercontractility, ${ }^{64}$ mucus hypersecretion, ${ }^{65}$ vasodilatation and increased vascular permeability. ${ }^{66}$ Acetylcholine released by parasympathetic neurons, ${ }^{67,68}$ and non-neuronal cells, such as epithelial cells, and fibroblasts ${ }^{69,70}$ can modulate airway inflammation and remodeling via M3 receptors. ${ }^{67,68}$ Additionally, acetylcholine from non-neuronal cells may contribute to corticosteroids in patients with COPD. ${ }^{10}$

Anticholinergic muscarinic receptor antagonists block the effects of acetylcholine at muscarinic receptors, especially M3. They have been used for the treatment of COPD for several years, and are now used as add-on treatment for severe uncontrolled asthma. ${ }^{71}$ They are initiated at the Global Initiative for Asthma (GINA) strategy step 4 or 5 with or without biologics. ${ }^{72}$ Currently, there are no biologics which have proven efficacy in the add-on treatment of COPD.

\section{Precision treatment of COPD}

Treatment of severe COPD is difficult because of the complexity and heterogeneity mechanisms of airway remodeling, which is responsible for the partial or total irreversible airway obstruction, and progressive decline in lung function. ${ }^{7-14}$ Targeted therapies for COPD should include pharmacological agents that relieve bronchoconstriction due to hypercontractility of ASM cells; drugs that decrease parasympathetic cholinergic activity, and anti-inflammatory agents.

Despite access to the most up-to-date medicines currently available treatment of COPD is inadequate. ${ }^{73}$ The Global Initiative for Chronic Obstructive Lung Disease (GOLD) 2020 Strategy report recommends a personalized approach for the management and treatment of COPD. The GOLD management strategy recommends treatment COPD according to the severity of the disease, annual rates of exacerbation, and pulmonary function (GOLD stage 1-4). The GOLD algorithm involves stepping up treatment from SABA or LABA, and adding a LAMA (LABA/LAMA), or an ICS (LABA/ICS). If symptoms persist, the algorism recommends addition of ICS to LABA/LAMA regimen, or use a single-inhaler triple therapy consisting of LABA/LAMA/ICS (SITT). ${ }^{74}$ Despite strict adherence and proper inhaler technique some patients with COPD are uncontrolled at stage 2 of the GOLD step-up regimen, thus initiating ICS, preferably in combination with LABA/ LAMA in the form of SITT. The GOLD stages for chronic obstructive pulmonary disease are shown in Table 3.

Table 3 GOLD strategies in the management of chronic obstructive pulmonary disease

\begin{tabular}{clll}
\hline Stage & $\begin{array}{l}\text { Clinical } \\
\text { presentation }\end{array}$ & FEVI & Treatment \\
\hline Stage I & Mild & $\geq 80 \%$ & SABA, LABA or LAMA \\
Stage 2 & Moderate & $50-79 \%$ & LABA/LAMA \\
Stage 3 & Severe & $30-49 \%$ & LABA/LAMA or LABA/ICS \\
Stage 4 & Very severe & $\geq 30 \%$ & LABA/LAMA/ICS, or SITT \\
\hline
\end{tabular}

\section{Single-inhaler triple therapy}

Single-inhaler triple therapy consisting of LABA, LAMA, and ICS have potent synergistic effect, and favourable pharmacological interaction in the treatment of COPD. ${ }^{75}$ LABA and LAMA bronchodilation effects are additive and may produce more bronchodilation at lower dosages of the two agents, thus minimizing side effects. Furthermore, addition of LAMA to LABA/ ICS combination may have anti-remodeling activity in addition to bronchodilation and anti-inflammatory activity. ${ }^{76}$ Long-acting muscarinic receptor antagonists have been shown to have antiinflammatory and anti-remodeling effects in mice model of COPD. ${ }^{77,78}$ LAMA have also been demonstrated to inhibit cigarette smokeinduced mucin hypersecretion in human bronchial epithelial cells, ${ }^{79}$ and inhibit cigarette smoke-induced lung fibroblast proliferation. ${ }^{80}$ Milara et al. ${ }^{81}$ have shown that aclidinium, an inhaled, long-acting muscarinic antagonist attenuates airway remodeling by decreasing expression of myofibroblast markers, such as collagen type 1, and $\alpha$-smooth muscle actin.

Currently, there are three single-inhaler triple therapy combinations which have been approved by the Food and Drug Administration (FDA) for maintenance treatment of COPD. They include: beclomethasone propionate/formoterol/glycopyrronium, budesonide/formoterol/ glycopyrronium, and fluticasonefuorate/vilanterol/umeclidinium (Table 4). The GOLD strategy recommends initiation of SITT at stage 4 (very severe COPD, with frequent exacerbations, and FEV1 $\leq$ $30 \%) .{ }^{74}$ Triple combination (LABA/LAMA/ICS) inhalers have been shown to significantly improve asthma symptoms control, reduce the frequency of moderate and severe exacerbations, and improve lung function compared with LAMA alone, and LABA/LAMA, or LABA/ ICS single-inhaler dual therapy. ${ }^{76,82-90}$ SITT has been reported to reduce hospitalization due to COPD exacerbations, significantly improve the health-related quality of life. ${ }^{85,90}$ with encouraging data suggesting a reduction in all-case mortality. ${ }^{91}$ Noteworthy, SITT is convenient for patients, and may improve compliance.

Single-inhaler triple therapy should not be recommended to all patients with severe COPD, and should be personalized according to the GOLD strategy. ${ }^{74}$ SITT is associated with adverse effects, and may be contraindication in some patients with co-morbidities with COPD. Overall, the benefit/risk profile of SITT outweighs the high risks of pneumonia due to the immunosuppressive effects of ICS, ${ }^{89}$ which has been reported in some studies. ${ }^{82-85,87}$ 
Table 4 Single-inhaler dual and triple therapy combinations for the treatment of chronic obstructive pulmonary disease

Single-inhaler dual therapy - LABA/LAMA
Formoterol/glycopyrronium
Formoterol - aclidinium
Indacaterol/glycopyrronium
Vilaterol/umeclidinium
Olodaterol/tiotropium
Single-inhaler dual therapy - LABA/ICS
Salmeterol/fluticasone propionate
Formoterol/beclomethasone dipropionate
Formeterol/budesonide
Formeterol/mometasone
Vilanterol/fluticasone fuorate
Indacaterol/mometasone
Single-inhaler triple therapy - LABA/LAMA/ICS
Beclomethasone dipropionate/formeterol/glycopyrronium
Budesonide/formoterol/gylcopyrronium
Fluticasone fuorate/vilanterol/umeclidinium

COPD patients with high eosinophil count $\geq 300$ cell. $\mu 1^{-1}$, and elevated biomarkers of Th2 inflammation, such as fractional exhaled nitric oxide ( $\mathrm{FeNO} \geq 50 \mathrm{ppb}$ ) response more favourably to SITT. The GOLD strategy recommends use of eosinophil count and FeNO in considering initiation of SITT. ${ }^{74}$ Conversely, eosinopenia (eosinophil count $<100$ cell. $\mu 1-1)$ increases the risk of pneumonia in patients with COPD, ${ }^{92-94}$ and ideally patients with eosinopenia should not be recommended for SITT. Moreover, patient with an eosinophil count of 50-100 cells. $\mu \mathrm{l}^{-1}$ do not respond to ICS. ${ }^{95,96}$ Similarly, patients with bronchiectasis and recurrent respiratory infections, tuberculosis, and non-mycobacterial tuberculosis should not be initiated on maintenance SITT. ${ }^{94}$

The cardiovascular adverse effects of LABA and LAMA are synergistic, and SITT may not be suitable for patients with heart failure, mitral stenosis, cardiac arrhythmias, ischaemic heart disease, transient ischaemic attacks, ${ }^{97,98}$ and stroke. ${ }^{99}$ Additionally, patient with HIV/AIDS on antiretroviral (ARV) regimen should not be recommended for SITT because glucocorticoids inhibit metabolism of protease inhibitor ARVs, and may increase the risk of Cushing's syndrome. ${ }^{100}$

\section{Conclusion}

Chronic obstructive pulmonary disease represents an important public health challenge and a socio-economical problem that is preventable and treatable. Airway inflammation and remodeling play a key role in the pathogenesis of COPD, airway narrowing, increase in airway resistance, and progressive decline in pulmonary function. Activated inflammatory, immune, and structural cells infiltrating the smaller airway secrete chemokines, cytokines, growth factors and enzymes which propagate airway remodeling. Inflammatory mediators and growth factors are responsible for the epithelial mesenchymal transition which is the initiator of airway remodeling.
There is increased parasympathetic cholinergic activity in the airways of patients with COPD. Targeted and personalized treatment of COPD should include bronchodilators, anti-inflammatory and antiremodeling agents. Single-inhaler triple therapy has been shown to significantly improve symptoms control, reduce moderate and severe exacerbations, and improve lung function. However, maintenance SITT should not be initiated in patients where triple therapy is contraindicated, such as tuberculosis, cardiac failure, and osteoporosis.

\section{Acknowledgments}

None.

\section{Conflicts of interest}

None.

\section{References}

1. GBD 2016 Cause of Death Collaborators. Global, regional, and national age-sex specific mortality for 264 causes of death, 1980-2016: a systemic analysis for the Global Burden of Disease Study 2016. Lancet. 2017;390:1151-1210.

2. Singh D, Agusti A, Anzueto A, et al. Global Strategy for the Diagnosis, Management, and Prevention of Chronic Obstructive Lung Disease: the GOLD science committee report 2019. Eur Respir J. 2019;53:1900164.

3. Buist AS, McBurnie MA, Vollmer WM, et al. International variation in the prevalence of COPD (The BOLD Study): a population-based prevalence study. Lancet. 2007;370:741-750.

4. van Eerd, van der Meer RM, van Schayck OC, et al. Smoking cessation for people with chronic obstructive pulmonary disease. Cochrane Database Syst Rev. 2016;8:CD010744.

5. Fraeser K, Callinan JE, McHugh J, et al. Legislative smoking bans for reducing harms from secondhand smoke exposure, smoking prevalence and tobacco consumption. Cochrane Database Syst Rev. 2016;24:3244-3254.

6. Sethi JM, Rochester CL. Smoking and chronic obstructive pulmonary disease. Clin Chest Med. 2000;21(1):67-86.

7. Mathioudakis AG, Vanfleteren LEGW, Lahousse L, et al. Current developments and future directions in COPD. Eur Respir Rev. 2020;29(158):200289.

8. Hurst JR, Skolnik N, Hansen GJ, et al. Understanding the impact of chronic obstructive pulmonary disease exacerbations on health and quality of life. Eur J Intern Med. 2020;73:1-6.

9. Jeffrey PK. Remodeling in asthma and chronic obstructive lung disease. Am J Repir Crit Care Med. 2001;164(10 Pt 2):S28-S38.

10. Hogg JC. Pathology of airflow limitation in chronic obstructive disease. Lancet. 2004;364:21-27.

11. Hogg JC, Chu F, Utokaparch S, et al. The nature of small-airway obstruction in chronic obstructive pulmonary disease. $N$ Engl $J$ Med .2004;350(26):2645-2653

12. Pini L, Pinelli V, Modina D, et al. Central airways remodeling in COPD patients. Int J Chron Obstruct Pulmon Dis. 2014;9:927-932.

13. Jones RL, Noble PB, Elliot JG, et al. Airway remodeling in COPD: It's not asthma! Respirology. 2016;21(8):1347-1356.

14. James A. Airway remodeling in asthma. Curr Opin Pulm Med. 2005;11(1):1-6.

15. Vestbo J, Hurd SS, Agusti AG, et al. Global strategy for the diagnosis, management, and prevention of chronic obstructive pulmonary disease. GOLD executive summary. Am J Respir Crit Care Med. 2013;187(4):347-365. 
16. Kirkham S, Kolsum U, Rousseau K, et al. MUC5B is the major mucin in the gel phase of sputum in chronic obstructive pulmonary disease. $A m \mathrm{~J}$ Respir Crit Care Med. 2008;178:1033-1039.

17. Burgel PR, Nadel JA. Roles of epidermal growth factor activation in epithelial cell repair and mucin production in airway epithelium. Thorax. 2004;59:992-996.

18. Calabrese C, Boccino V, Vatrella A, et al. Evidence of angiogenesis in bronchial biopsies of smokers with or without airway obstruction. Respir Med. 2006;100(8):1415-1422.

19. Siafakas NM, Antoniou KM, Tzortzaki EG. Role of angiogenesis and vascular remodeling in chronic obstructive pulmonary disease. Int J Chron Obstruct Pulmon Dis. 2007;2(4):453-462.

20. Gross NJ, Skorodin MS. Role of the parasympathetic system in airway obstruction due to emphysema. N Engl J Med. 1984;311(7):421-425.

21. Washko GR, Hunninghake GM, Fernandez IE, et al. Lung volumes and emphysema in smokers with interstitial lung abnormalities. N Engl J Med. 2011;364(10):897-906.

22. Sze MA,Dimitriu A, Suzuki M, et al. Host response to microbiome in chronic obstructive pulmonary disease. Am J Respir Crit Care Med. 2015;192(4):438-445

23. Colebatch HJ, Finucane KE, Smith MM. Pulmonary conductance and recoil relationships in asthma and emphysema. J Appl Physiol. $1973 ; 34: 143-153$

24. Hogg JC, Timens W. The pathology of obstructive pulmonary disease Annu Rev Pathol. 2009;4:435-459.

25. Sohal SS, Ward S, Danial W, et al. Recent advances in understanding inflammation and remodeling in the airways in chronic obstructive pulmonary disease. Expert Rev Respir Med. 2013;7(3):275-288.

26. Wang $\mathrm{Y}, \mathrm{Xu} \mathrm{J}$, Meng $\mathrm{Y}$, et al. Role of inflammatory cells in airway remodeling in COPD. Int J Chron Obstruct Pulmon Dis. 2018;13:334-348.

27. Saetta M, Di Stefano A, Turato G, et al. CD8+ T-lymphocytes in peripheral airways of smokers with chronic obstructive pulmonary disease. Am J Respir Crit Care Med. 1998;157(3 Pt 1):822-826.

28. Barnes PJ. Inflammatory mechanisms in patients with chronic obstructive pulmonary disease. J Allergy Clin Immunol. 2016;138:16-27.

29. Grzela K, Litwiniuk M, Zagorska W, et al. Airway remodeling in chronic obstructive pulmonary disease and asthma: The role of matrix metalloproteinase-9. Arch Immunol Ther Exp (Warsz). 2016;64(1):47-55.

30. Wright DB, Meurs K, Dekkers BG. Integrins: Therapeutic targets in airway hyperresponsiveness and remodelling? Trends Pharmacol Sci. 2014;35:567-574

31. Byzova TY, Goldman CK, Pampori N, et al. A mechanism for modulation of cellular responses to VEGF. Activation of integrins. Mol Cell. 2000;6(4):851-860

32. Liu ZJ, Snyder R, Soma A, et al. VEGF-A and $\alpha v \beta$ integrin synergistically rescue angiogenesis via $\mathrm{N}-\mathrm{Ras}$ and $\mathrm{PI} 3-\mathrm{K}$ signaling in human microvascular endothelial cells. FASEB J. 2003;17:1931-1933.

33. Chung KF. Cytokines in chronic obstructive pulmonary disease. Eur Respir J. 2001;18:50s-59s.

34. de Boer WI. Cytokines and therapy in COPD: A promising combination. Chest. 2002;121:209-218.

35. Di Stefano A, Capelli A, Donner CF. Role of interleukin-8 in the pathogenesis and treatment of COPD. Chest. 2004;126(3):676-679.

36. Garth J, Barnes JW, Krick S. Targeting cytokines as evolving treatment strategies in chronic inflammatory airway diseases. Int $\mathrm{J} \mathrm{Mol} \mathrm{Sci}$. 2028;19(1):3402.
37. Chung KF. Inflammatory mediators in chronic obstructive pulmonary disease. Curr Drug Targets Inflamm Allergy. 2005;4(6):619-625.

38. Kranenburg AR, Williems-Widyastuti A, Mooi WJ, et al. Chronic obstructive pulmonary disease is associated with enhanced bronchial expression of FGF-1, FGF-2, and FGFR-1. J Pathol. 2005;206(1):28-38.

39. Burgel PR, Nadel JA. Epidermal growth factor receptor-mediated innate immune responses and their role in airway diseases. Eur Repir J. 2008;32(4):1068-1081.

40. di Stefano A, Sangiorgi C, Gnemmi I, et al. TGF-beta signaling in different compartments of the lower airways of patients with stable COPD. Chest 2018;153(4):851-862.

41. Hallstrand TS, Hackett TL, Altemeier WA, et al. Airway epithelial regulation of pulmonary immune homeostasis and inflammation. Clin Immunol (Orlando, Fla). 2014;151(1):1-15.

42. Puchelle E, Zahm JM, Tournier JM, et al. Airway epithelial repair, regeneration, and remodeling after injury in chronic obstructive pulmonary disease. Proc Am Thorac Soc. 2006;3(8):726-733.

43. Holgate ST, Lackie PM, Davies DE, et al. The bronchial epithelium as a key regulator of airway inflammation and remodeling in asthma. Clin Exp Allergy. 1999;29(Suppl 2):90-95.

44. Puddicombe SM, Polosa R, Richter A, et al. Involvement of the epiderma growth factor in epithelial repair in asthma. FASEB J. 2000;14:1362-1374.

45. Shayhiev R, Crystal RG. Early events in the pathogenesis of chronic obstructive pulmonary disease. Smoking-induced reprogramming of airway epithelial basal progenitor cells. Ann Am Thorac Soc. 2014;11(Suppl 5):S252-S259.

46. Sohal SS. Airway basal cell reprogramming and EMT: potential key to understanding early COPD. Am J Respir Crit Care Med. 2018;197:1644-1645

47. Sohal SS, Reid D, Soltani A, et al. Reticular basement fragmentation and potential epithelial mesenchymal transition is exaggerated in the airways of smokers with chronic obstructive pulmonary disease. Respirology. 2010;15(6):930-938.

48. Sohal SS, Walters EH. Role of epithelial mesenchymal transition (EMT) in chronic obstructive pulmonary disease (COPD). Respir Res. 2013;14(1):120

49. Nowrin K, Sohal SS, Peterson G, et al. Epithelial-mesenchymal transition as a fundamental underlying pathogenic process in COPD airways: fibrosis, remodeling and cancer. Expert Rev Respir Med. 2014;8(5):547-559.

50. Courtney J-M, Spafford PL. The role of epithelial-mesenchymal transition in chronic obstructive pulmonary disease. Cells Tissues Organs. 2017;203(2):99-104.

51. Aghapour M, Raee P, Moghaddam SJ , et al. Airway epithelial barrier dysfunction in chronic obstructive pulmonary disease: role of cigarette smoke exposure. Am J Respir Cell Mol Biol. 2017;58(2):157-169.

52. Wang Q, Wang Y, Zhang Y, et al. The role of uPAR in epithelialmesenchymal transition in small airway epithelium of patients with chronic obstructive pulmonary disease. Repir Res. 2013;14(1):67.

53. Gohy ST, Hupin C, Fregimilicka C, et al. Imprinting of the COPD airway epithelium for dedifferentiation and mesenchymal transition. Eur Repir J. 2015;45:1258-1272.

54. Courtney J-M, Spafford P, Sohal SS, et al. TGF $\beta$-induced epithelial to mesenchymal transition (EMT) as a model of COPD. Eur Respir J. 2016;48:PS953;

55. Mahmood A, Noor WD, Muller HK,et al. Epithelial mesenchymal transition in smokers: large versus small airways and relation to airflow obstruction. Int J Chron Obstruct Pulmon Dis. 2015;10:1515-1524. 
56. Milara J, Peiró T, Serrano A, et al. Epithelial to mesenchymal transition is increased in patients with COPD and induced by cigarette smoke. Thorax. 2013;68(5):410-420.

57. Scotton CJ, Chambers RC. Molecular targets in pulmonary fibrosis: the myofibroblast in focus. Chest. 2007;132:1311-1321.

58. Singh SR, Hall IP. Airway myofibroblasts and their relationship with airway myocytes and fibroblasts. Proc Am Thorac Soc. 2004;1:176-183.

59. Milara J, Serrano A, Peiró T, et al. Aclidinium inhibits cigarette smokeinduced lung fibroblast-to-myofibroblast transition. Eur Respir $J$. 2013;41:1264-1274.

60. Gross NJ, Skorodin MS. Role of the parasympathetic system in airway obstruction due to emphysema. N Engl J Med. 1984;311:421-425.

61. Barnes PJ. Muscarinic receptor subtypes in airways. Life Sci. 1993;52(56):521-527

62. Zaagma J, Roffel AR, Meurs H. Muscarinic control of airway function Life Sci. 1997;60(13-14):1061-1068.

63. Belmonte KE. Cholinergic pathways in the lungs and anticholinergic therapy for chronic obstructive pulmonary disease. Proc Am Thorac Soc. 2005;2:297-304.

64. Colebatch HJH, Halmagyi DFJ. Effect of vagotomy and vagal stimulation on lung mechanics and circulation. J Appl Physiol. 1963;18:881-887.

65. Baker B, Peatfield AC, Richardson PS. Nervous control of mucin secretion into human bronchi. J Physiol. 1985;365:297-305.

66. Laitinen LA, Laitinen MV, Widdicombe JG. Parasympathetic nervous control of tracheal vascular resistance in the dog. $J$ Physiol 1987;385:135-146

67. Scott GD, Fryer AD. Role of parasympathetic nerves and muscarinic receptors in allergy and asthma. Chem Immunol Allergy. 2012;98:48-69.

68. Yamada M, Ichinose M. The cholinergic pathway in inflammation: a potential pharmacotherapeutic target for COPD. Front Pharmacol. 2018;9:1426

69. Gwilt CR, Donnelly LE, Rogers DF. The non-neuronal cholinergic system in the airways: an unappreciated regulatory role in pulmonary inflammation? Pharmacol Ther. 2007;115(2):208-222.

70. Milara J, Cervera A, de Diego A, et al. Non-neuronal cholinergic system contributes to corticosteroid resistance in chronic obstructive pulmonary disease patients. Respir Res. 2016;17(1):145.

71. Busse WW, Dahl R, Jenkins C, et al. Long-acting muscarinic antagonists: a potential add-on therapy in the treatment of asthma? Eur Respir Rev. 2016;25:54-64

72. Global Initiative for Asthma. Global strategy for asthma management and prevention. 2020

73. Gross NJ, Barnes PJ. New therapies for asthma and chronic obstructive pulmonary disease. Am J Respir Crit Care Med. 2016;195(2);159-166.

74. Global initiative for chronic obstructive lung disease. Global strategy for the diagnosis, management, and prevention of chronic obstructive pulmonary disease. 2021 Report.

75. Matera MG, Page CP, Calzetta L, et al. Pharmacology and therapeutics of bronchodilators revisited. Pharmacol Rev. 2020;72(1):218-252.

76. Matera MG, Rogliani P, Calzetta L, et al. Triple combination inhalers in chronic obstructive pulmonary disease. Respir Pulmon Dis. 2020;5(1):18-23.

77. Wollin L, Pieper MP. Tiotropium bromide exerts anti-inflammatory activity in a cigarette smoke mouse model of COPD. Pulm Phramacol Ther. 2010;23(4):345-354.
78. Hsiao $\mathrm{YH}$, Tseng $\mathrm{CM}$, Su KC, et al. Glycopyrronium bromide inhibits lung inflammation and small airway remodeling induced by subchronic cigarette exposure in mice. Respir Physiol Neurobiol. 2018;249:16-22.

79. Cortijo J, Mata M, Milara J, et al. Aclidinium inhibits cholinergic and tobacco smoke induced MUC5AC in human airways. Eur Respir J. 2011;37(2):244-254.

80. Profita M, Bonanno A, Siena L, et al. Smoke, choline acetyltransferase, muscarinic receptors and fibroblast proliferation in chronic obstructive pulmonary disease. J Pharmacol Exp Ther. 2009;329:753-763.

81. Milara J, Serrano A, Peiro T, et al. Aclidinium inhibits cigarette smokeinduced lung fibroblast-to-mesenchymal transition. Eur Respir J. 2013;41:1264-1274.

82. Singh D, Papi A, Corradi M, et al. Single inhaler triple therapy versus inhaled corticosteroid plus long-acting $\beta 2$-agonist therapy for chronic obstructive pulmonary disease (TRILOGY): a double-blind, parallel group, randomised controlled trial. Lancet. 2016;388:963-973.

83. Vestbo J, Papi A, Corradi M, et al. Single inhaler extrafine triple therapy versus long-action muscarinic antagonist therapy for chronic obstructive pulmonary disease (TRINITY): a double-blind, parallel group, randomised controlled trial. Lancet. 2017;389:1919-1929.

84. Papi A, Vestbo J, Fabbri L, et al. Extrafine inhaled triple therapy versus dual bronchodilator therapy in chronic obstructive pulmonary disease (TRIBUTE): a double-blind, parallel group, randomised controlled trail. Lancet. 2018;391:1076-1084.

85. Lipson DA, Barnhart F, Brealey N, et al. Once-daily single-inhaler triple versus dual therapy in patients with COPD. $N$ Engl $\mathrm{J} \mathrm{Med}$. 2018;378:1671-1680.

86. Ferguson GT, Rabe KF, Martinez FJ, et al. Triple therapy with budesonide/ glycopyrrolate/formoterol fumarate with co-suspension deliverly technology versus dual therapies in chronic obstructive pulmonary disease (KRONOS): a double-blind, parallel-group, multicentre, phase 3 randomised controlled trial. Lancet Respir Med. 2018;6(10):747-758.

87. Langham S, Lewis J, Pooley N, et al. Single-inhaler triple therapy in patients with chronic obstructive pulmonary disease: a systemic review. Respir Med. 2019;20:242

88. Rabe KF, Martinez FJ, Ferguson GT, et al. Triple inhaled therapy at two glucocorticoid doses in moderate-to-severe COPD (ETHOS). $N$ Engl $J$ Med. 2020;383(1):35-48.

89. Voorham J, Corradi M, Papi A, et al. Comparative effectiveness of triple therapy versus dual bronchodilation in COPD. ERJ Open Res. 2019;5(3):00106-2019.

90. Boubeau J, Bafadhel M, Barnes NC, et al. Benefit/risk profile of singleinhaler triple therapy in COPD. Int $J$ Chron Obstruct Pulmon Dis. 2021;16:499-517

91. Lipson DA, Crin C, Criner GJ, et al. Reduction in all-case mortality with fluticasone fuorate/umeclidinium/vilanterol in COPD patients. $\mathrm{Am} \mathrm{J}$ Respir Crit Care Med. 2020;201(12):1503-1516.

92. Ernst B. Blood eosinophils in COPD and the risk of pneumonia. Eur Respir J. 2018;52:1800981.

93. Pavord ID, Lettis S, Anzueto A, et al. Blood eosinophil count and pneumonia risk in patients with chronic obstructive pulmonary disease: a patient-level meta-analysis. Lancet Respir Med. 2016;4:731-741.

94. Vanfleteren LEGW, Ullman A, Nordenson A, et al. Triple therapy (ICS/ LABA/LAMA) in COPD: thinking out of the box. ERJ Open Res. 2019:5:00185-2018.

95. Bafadhel M, Pavord ID, Russell REK. Eosinophils in COPD: just another biomarker? Lancet Respir Med. 2017;5:747-759. 
96. Pascoe S, Lacantone N, Dransfield MT, et al. Blood eosinophil counts, exacerbations, and response to the addition of fluticasone fuorate to vilanterol in patients with chronic obstructive pulmonary disease: secondary analysis of data from two parallel controlled trials. Lancet Respir Med . 2015;3:435-442.

97. Suissa S, Dell'Aniello S, Ernst P. Coccurent use of long-acting bronchodilators in COPD and risk of adverse cardiovascular events. Eur Respir J. 2017;49;1602245.

98. Rogliani P, Matera MG, Ora J, et al. The impact of dual bronchodilation on cardiovascular serious events and mortality in COPD: a quantitative synthesis. Int J Chron Obstruct Pulmon Dis. 2017:12:3469-3485.
99. Wang MT, Tsai CL, Lo YW, et al. Risk of stroke associated with inhaled ipratropium bromide in chronic obstructive pulmonary disease: a population based nested case-controlled study. Int J Cardiol. 2013;158(2):279-284.

100. Elliot ER, Theodoraki A, Jain LR. Iatrogenic Cushing's syndrome due to drug interaction between glucocorticoids and ritonavir or cobicistat containing HIV therapies. Clin Med (Lond). 2016;16:412-418. 